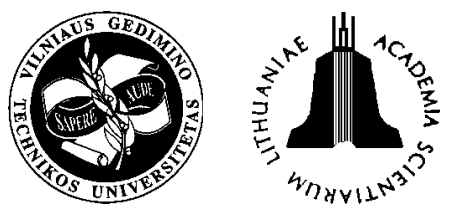

ISSN 1648-4142 TRANSPORT

\title{
THE ASPECTS OF POSSIBILITY TO APPLY ALTERNATIVE FUEL INJECTION SYSTEMS
}

\author{
Vytenis Naginevičius ${ }^{1}$, Vitas Lendraitis ${ }^{2}$ \\ ${ }^{1}$ Kaunas Technical College, Tvirtoves al.35, LT-3009 Kaunas, Lithuania.E-mail: ktk@ktk.lt \\ ${ }^{2}$ Kaunas University of Technology, Kęstučio g.27, LT-3004 Kaunas, Lithuania.E-mail: vitas.lendraitis@ktu.lt
}

Received 2004-01-30; accepted 2004-04-15

\begin{abstract}
In the report the short review of the constructional peculiarities of electro-magnetic fuel injectors is discussed. The alternative mechanism constructions operated by vibrations and their operation principles are described. The mathematical model of the system is created. The motion existence conditions as well as stable and unstable moving element positions in the system are analyzed. The vibration excitation schemes in the standing wave mode and changing the tube fastening modes in the system are reviewed. The perspectives of new construction development and application are defined.
\end{abstract}

Keywords: valve-injector, stability, condition of motion, frequency, model.

\section{Introduction}

Modern automobiles (mostly Otto engines) use electro magnetic injectors to inject fuel. Their construction [1] and control, using the widened modulation are rather complicated because of electro magnetic histerisis [2]. To provide the sureness the comparably complicated tasks are solved. We are going to discuss in more detail the constructional and operational principle of the alternative equipment which performs the functions of the fluid flow and spraying valve. We have in mind the vibratory valves the sealing element of which gets the power from the vibrating element, such as the sealing seat or the body of the equipment.

The greatest advantages of this equipment group are the constructional simplicity, fast speed and the application without any special requirements for the fuel batching accuracy.

The disadvantages could be a relatively small run of the sealing element regarding the valve seat and the fact that the sealing element occupies unspecified position in time for the direction predicted, i.e. the position of the sealing element is not fixed when the valve is opened. This eliminates the possibility to precisely regulate the debit of the fuel flow through the seat. Besides, when the exiting element works at high frequencies, the springing of the sealing element from the valve seat is possible when the valve is closed. This happens because of great difference between the selffrequencies in the sealing element - a valve seat and a sealing element - spring systems.
The main advantages of this vibratory equipment show the wide potential of its application especially when there is a possibility to design constructions which provide the high run of the sealing element and its fixed position regarding the valve seat.

Considering this fact, the patterns of the alternative fuel injection systems mechanisms are designed and tested at KTK. The goal of this activity is to provide teachers' and students' scientific research and, to some extent, look for the realization of the results in practice through scientific agreements.

\section{New constructions}

We introduce the construction of the vibratory valve-injector based on the original operational principle (Fig 1). Its purpose is to replace the electro magnetic fuel injector of complicated construction which was discussed earlier. Our aim is to create a mathematical model of the valve-injector, to analyze the sealing element stability in the tube of the vibratory valve, to define the conditions for the motion, to select the place for the valve seat fastening and to calculate the standing wave stimulation modes in the tube selecting the electromechanical converter and taking into consideration the result analysis to optimize the constructional parameters and control modes.

The mathematical model of the valve-injector allows to explain its principle of operation, i.e. to describe the motion of the sealing element in the tube when the 


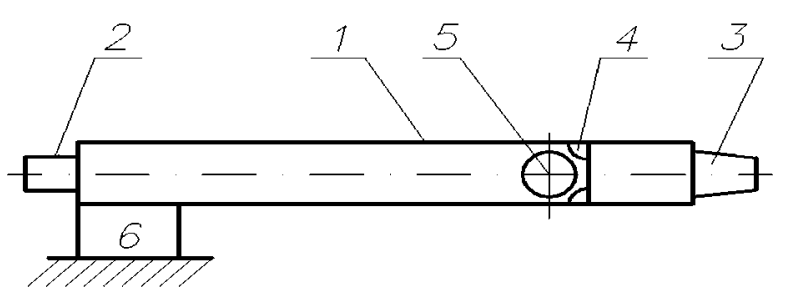

Fig 1. Vibratory valve-injector [3]

It is made of a tough thin-wall tube 1, input (inlet) channel 2, output (outlet) channel-injector 3 , valve seat 4 , sealing element 5 and vibration source 6

vibration is stimulated and to make the differential motion equation of the sealing element (Fig 2). Here we presume that the sealing element is moving through the longitudinal axis of the tube, i.e. in the tangential direction.

In the case of diametrical and longitudinal vibration stimulation, it is described according to the following laws [4]:

$$
\begin{aligned}
& \xi=B \sin k(x+\eta) \sin \omega t \\
& \eta=A \cos k x \cos \omega t
\end{aligned}
$$

The differential motion equation is:

$$
M\left(\frac{d^{2} u}{d t^{2}}+\frac{d^{2} v}{d t^{2}} \frac{\delta \xi}{\delta u}\right)+\left[1+\left(\frac{\delta \xi}{\delta u}\right)^{2}\right]^{1 / 2}(H+P)=0,
$$

where $u=x+\eta, v-$ motion coordinates of the absolute sealing element; $\mathrm{H}$ - motion resistance force; $P$ - force, produced by external pressure; $A$ and $B$-longitudinal and diametrical vibration amplitudes accordingly; $M$ sealing element mass; $\omega$-vibration frequency.

$$
k=\sqrt[4]{\frac{m \omega^{2}}{E I}},
$$

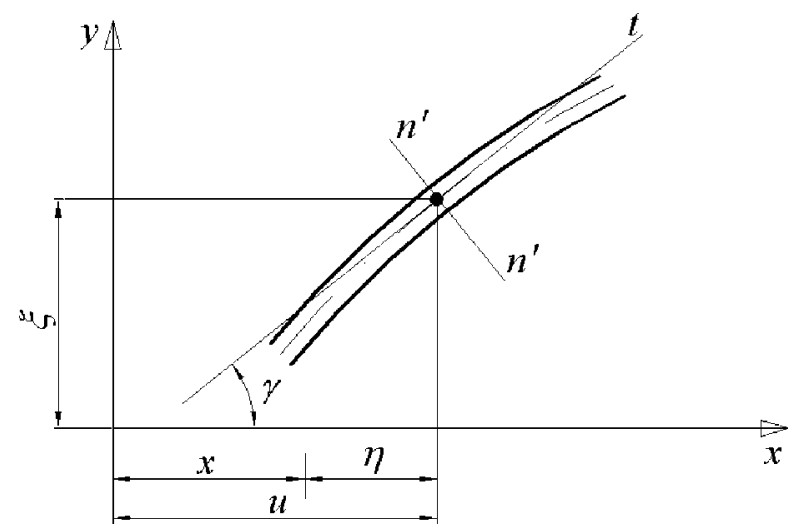

Fig 2. Valve mathematical model where $E$ - Jung module of the tube material; $I$ - tube cross-section inertia radius; $m$ - tube mass (a unit of length).

In the case when $A=0$ and only diametrical vibrations of standing waves are stimulated in the tube, we can determine the condition of the motion existence:

$$
\frac{P}{0,25 \omega^{2} M k B^{2}}=\sin 2 k x
$$

or,

$$
\left|\frac{P}{0,25 \omega^{2} M k B^{2}}\right|<1 \text {. }
$$

This means that the pressure force $P$ decreases and $\omega, M$ and $B$ increase the area of motion existence. This shows that if a definite pressure force $P$ is present, to overcome it the sealing element the mass of which is $M$, should get the appropriate frequency w and amplitude $B$ with the help of tube vibrations. This raises the requirements for the source of the vibration stimulation the importance of which we are going to discuss later.

The graphical interpretation of the conditions for the motion existence is presented in Fig 3.

The range over the curve 1 exists when the duct vibration frequency $f=1060 \mathrm{~Hz}, k=0,44$;

The range over the curve $2-$ when $f=2100 \mathrm{~Hz}$, $k=0,55$; 0,66 ;

The range over the curve $3-$ when $f=3260 \mathrm{~Hz}, k=$

The range over the curve $4-$ when $f=5600 \mathrm{~Hz}$, $k=0,7$.

In the process of the differential equation solving [5], we find that the condition for the closing element stability regarding the axis $\mathrm{x}$ is $\cos 2 k x<0$.

In the case when $P>0$ and the condition for the motion existence is met, the values

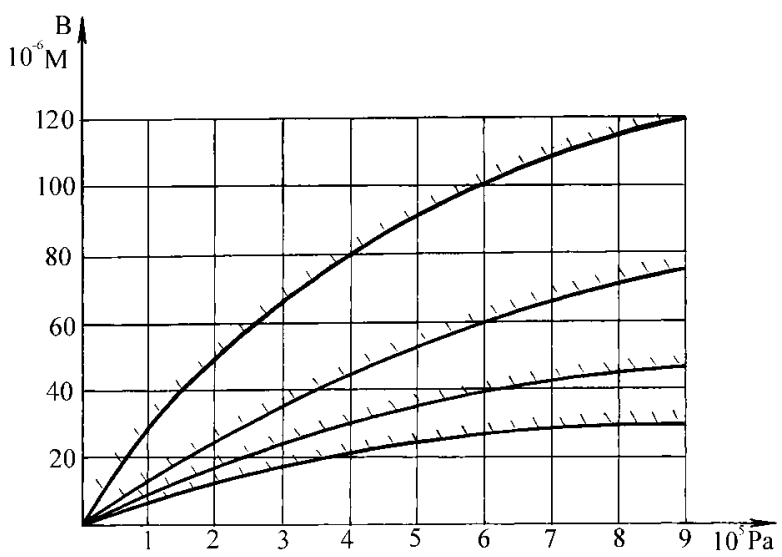

Fig 3. The conditions for the existence of the sealing element motion in the tube 
$x_{1}=\frac{1}{2 k} \arcsin \frac{P}{0,25 \omega^{2} M k B^{2}} \in\left(0+\frac{\pi n}{k} ; \frac{2 \pi}{4 k}+\frac{\pi n}{k}\right)$

are unstable, and

$$
x_{2}=\frac{\pi n}{2 k}-x_{1}
$$

is stable.

Here $n=1,2,3, \ldots, n$-whole number.

These values occur periodically along the tube length.

Having calculated these values and having the conditions of the sealing element motion existence, we can explain the principle of the valve operation. Fig 4 helps to illustrate it.

The operation principle is based on the excitation of the diametrical vibrations in the tough tube, creating the standing wave (Fig 4). In order to increase the vibration amplitude the frequency of the forced vibration source 6 (Fig 1) must synchronize with the tube, for example, the second vibration forms frequency. The sealing element affected by the tube vibrations overcomes the force $P$, created by the pressure and moves from the unstable position (from $x_{1}$ to $x_{2}$ ) to the stable position $x_{2}$, which is at the maximum of the tube vibration amplitude, so meeting the condition of the motion existence (Fig 4b).The valve is opened and the fuel, passing through the valve seat is splashed with the help of vibration and the special nozzle. The valve is closed opening the electrical control signal to the stimulation source [5]. The force $\mathrm{P}$ presses the sealing element to the valve seat (Fig 2).

The main evaluation criteria of the vibratory valve operation are the motion law of the sealing element during the transition process $x(t)$, the speed of the sealing element $x(\mathrm{t})$, the length of the transition process and the vibratory valve going off time $t_{p}$, i.e. high-speeding (Fig 5).

The length of the transition process is defined as the time from the beginning of the process till the moment when the inequality is met:

$$
|x(t)-x(\infty)| \leq \Delta x(\infty)
$$
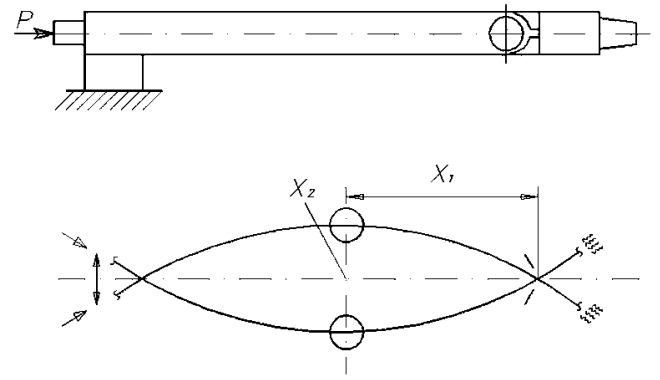

Fig 4. Valve - injector operation principle

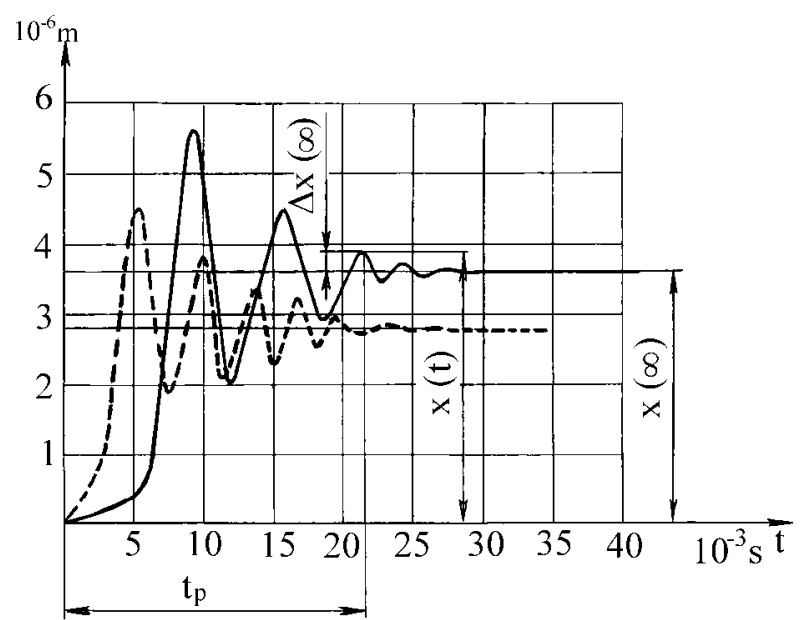

Fig 5. The motion law of the sealing element when two self- vibration frequencies of the tube exist

Here $\Delta x(\infty)$ is the value which makes about 10 $30 \%$ of the first leap value in the automatic control system.

Going off time $t_{s}$ is the sealing element moving time from the seat at the length $x_{s}$., which depends on the cross-sectional area of the sealing element and provides the fluid flow through the seat without pressure losses, i.e. without throttle. $x_{s}$ is usually selected $x_{s} \geq d_{s} / s . d_{s}-$ seat leak cross-section.

The diagrams show that the length of the transition process goes down when self-vibrations are exited at higher frequencies.

Curve 1 - frequency $\mathrm{f}=1060 \mathrm{~Hz}$,

curve 2 - frequency $\mathrm{f}=2100 \mathrm{~Hz}$.

The conclusion can be made that the higher the wave number $k$, i.e. the higher frequency of the duct vibration, the lower vibratory valve going off time $t_{s}$.

In Fig 6 the length oh the transition process and the dependence on the vibration amplitude under three self-vibratory frequencies are presented.

The curve 1 corresponds to the frequency $\mathrm{f}=1060$ $\mathrm{Hz}$; the curve 2 corresponds to the frequency $\mathrm{f}=2100$ $\mathrm{Hz}$;

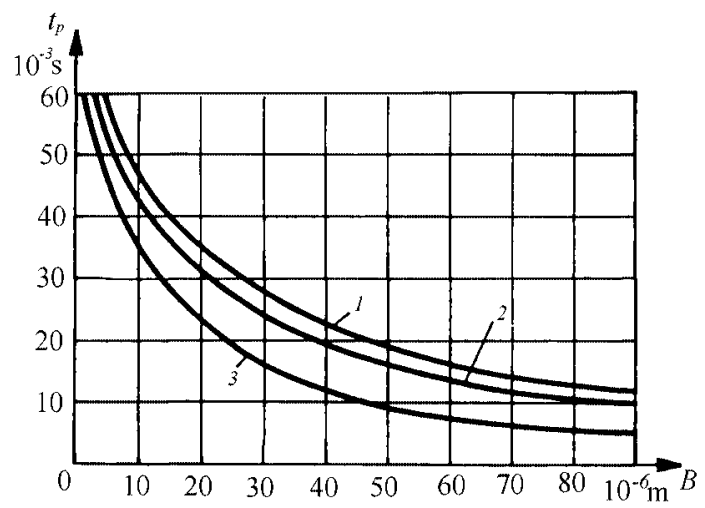

Fig 6. The length of the transition process and the dependence on the vibration 

Hz.

The curve 3 corresponds to the frequency $\mathrm{f}=3260$

The graphs illustrate the case when the increasing vibratory amplitude of the duct increases the length of the transition process and the run time of the vibratory valve goes down.

The calculations also show that the length of the transition process is slightly influenced by the coefficient of the resistance motion which depends on the swampiness of the fluid used.

For the excitation of the vibration the piezo-ceramic converters are used, selecting various excitation force adding places. Two of them are presented in Fig 7.
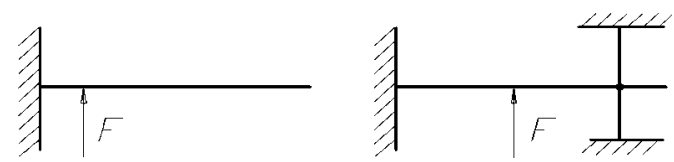

Fig 7. Schemes of excitation addition and tube fastening

The case $\mathrm{b}$ is more reliable in the automobile because it is tougher and more shockproof $b$. This provides the higher proper frequency which increases the opening force more efficiently than the vibration amplitude (see: Motion existence condition).

Piezo - ceramic converters are operated by the rectangular pulses which are generated from the supply.

The position of the tube vibration unit can be switched by changing fastening conditions, for example, fastening the source of the diametrical vibrations in the one end of the tube and the source of the longitudinal vibrations in the other end.

The construction with the variable inner cross-sectional area of the tube in comparison to its length provides the different debit of the fuel flowing. Here the closing element position is regulated by the vibration amplitude.

The vibrating valves have very simple construction and small dimensions. They are cheap, fast - moving, do not require special forms of control signals.

We introduce the technical characteristics of the valve-injector:

fuel pressure, bar

frequency of the resonant vibrations $\mathrm{kHz} \quad 5,6$

opening duration, $\mathrm{ms}$

2

power used, W

switching frequency, $\mathrm{Hz}$

2

dimensions, $\mathrm{mm}$

up to 100

$60 \times 10 \times 10$

\section{Perspectives of development}

The following disadvantages were noticed during the testing:

- $\quad$ piezo-ceramic converters provide relatively small vibration amplitude;
- fastening of fuel supply hose to the valve-injector remains problematic, what changes the toughness of the construction and the resonant vibration frequency.

That's why the main future development guideline is to improve the resonant converter construction which operates on higher frequencies and higher amplitudes and to work out the computer programs for the calculation of optimal tube constructional parameters.

In order to avoid the problems of fastening the fuel supply hose to the vibratory valve duct the principle of fastening the hose to the tube last plane in applied.

This principle in shown in Fig 8.

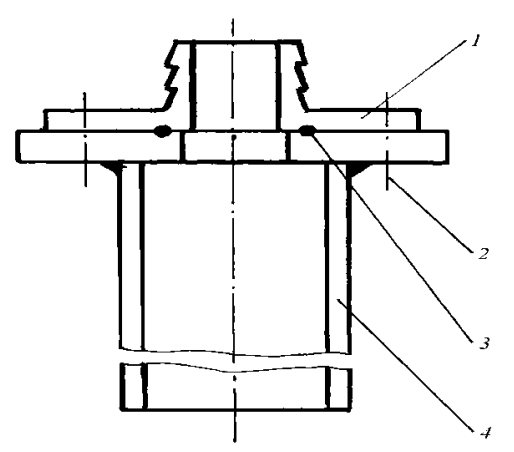

Fig 8. Principle of hose fastening: 1 - hose fastening cap, 2 - fastening element, 3 - seal, 4 - tube

\section{Conclusions}

The analysis of the valve-injector construction and operation principle shows the positive sides and the sides which need further improvement. At present it is hard for these constructions to compete with traditional ones because they are not fully investigated and unfamiliar, but they haven't lost the right to be further investigated and developed. The reason for this is their construction simplicity, small dimensions, cheapness and the variety of their application.

\section{References}

1. Isacsson, Ch. Dynamic valve characteristics: analysis and measurement methods. Linkoping University, 1996. $96 \mathrm{p}$.

2. James, E. Duffy Auto electricity and electronics technology: principles, diagnosis, testing, and service of all major electrical, electronic, and computer control systems. The Goodheart-Willcox Company, 1998. 574 p.

3. Ragulskis, K. M; Naginevičius, V. V. et al. The use of vibrovolue for the stream of liquid (Виброклапан для управления потоком жидкости. Авторское свидетельство СССР. № 2362505, кл. В 05 В 17/06, 1987) (in Russian).

4. Harold, Joseph; Ronald, L. Dynamics of mechanical systems. Huston CRC Press, 2002. 757 p.

5. Vinogradov, O. Fundamentals of kinematics and dynamics of machines and mechanisms. CRC Press, 2000. 290 p. 